Gut, 1974, 15, 947-952

\title{
Gluten-sensitive enteropathy: Synthesis of antigliadin antibody in vitro ${ }^{1}$
}

\section{Z. MYRON FALCHUK² AND WARREN STROBER}

From the Peter Bent Brigham Hospital, Boston, Massachusetts, and Metabolism Branch, National Cancer Institute, National Institutes of Health, Bethesda, Maryland

SUMMARY The intestinal mucosa of patients with gluten-sensitive enteropathy responds to gluten challenge in vivo with a striking increase in IgA and IgM synthesis. Whether this increase in immunoglobulin synthesis is due in some part to the production of antigliadin antibodies is examined. Using an affinity chromatography technique it has been demonstrated that in six of seven patients with gluten-sensitive enteropathy approximately half of the net increase in IgA and IgM synthesis occurring after gluten challenge can be attributed to the synthesis of antigliadin antibody. These data strengthen the hypothesis that immunological phenomena are related to the pathogenesis of glutensensitive enteropathy.

In a previous study of the role of immunological processes in the pathogenesis of gluten-sensitive enteropathy, we demonstrated that the intestinal mucosa of patients with this disorder responds to gluten challenge in vivo with a striking increase in IgA and IgM synthesis (Loeb, Strober, Falchuk, and Laster, 1971). If this increase were causally related to the lesion of gluten-sensitive enteropathy, we might expect a certain portion of the post-challenge immunoglobulin to have antigliadin activity. In the present investigation, we have evaluated this possibility by first measuring jejunal immunoglobulin (IgA and IgM)synthesis in biopsy specimens obtained from patients with gluten-sensitive enteropathy before and after a gluten challenge, and then measuring the fraction of this increase due to the synthesis of antigliadin antibody. The results indicate that biopsies from patients in remission do not produce antigliadin antibody, whereas biopsies from the same patients in exacerbation produce increased quantities of immunoglobulins, a large portion of which are antigliadin antibodies.

\footnotetext{
${ }^{1}$ Presented in part at the national meeting of the American Federation for Clinical Research 2 May 1971, and at the Second Coeliac Symposium, Leyden, Holland, 11 March 1974.

Portions of this work were carried out while Dr Falchuk was an Associate at the Digestive and Hereditary Diseases Branch, National Institute of Arthritis, Metabolism and Digestive Diseases, Bethesda, Maryland.
}

'Please send reprint requests to: Dr Z. Myron Falchuk, Peter Bent Brigham Hospital, 721 Huntington Avenue, Boston, Massachusetts 02115 .

Received for publication 14 August 1974.

\section{Methods}

GENERAL OUTLINE OF STUDY

Patients with gluten-sensitive enteropathy in remission were studied both immediately before and after an oral gluten challenge of six to 12 days. In each study intestinal biopsies were obtained and incubated in vitro with ${ }^{14} \mathrm{C}$-L-leucine. The biopsy tissues were then homogenized and centrifuged to yield a supernatant containing newly synthesized protein. The supernatant was assayed for ${ }^{14} \mathrm{C}-\lg \mathrm{A}$ and ${ }^{14} \mathrm{C}$-IgM by measuring the binding of labelled protein to bromacetyl cellulose-anti-immunoglobulin (BAC-anti-Ig), and for the presence of antigliadin antibody by measuring binding of radiolabelled protein to gliadin-Sepharose affinity columns.

\section{PATIENTS}

Seven patients (two males and five females) with gluten-sensitive enteropathy in remission were studied. The patients ranged in age from 9 to 55 years. The diagnosis was made on the basis of clinical and laboratory response to gluten restriction and reintroduction, the presence of fat and D-xylose malabsorption, and the histological demonstration of villous flattening and plasma cell and lymphocyte infiltration of the proximal jejunal mucosa.

\section{CONTROLS}

Seven normal individuals (six males and one female), as well as one patient with hypogammaglobulinaemia, were studied. The control individuals ranged in age from 21 to 45 years, and none, except the 
patient with hypogammaglobulinaemia, had clinical or laboratory evidence of malabsorption or maldigestion. Biopsies were obtained initially following two or three weeks on a gluten-free diet and again after two weeks on a gluten-containing diet. The purpose and possible hazards of the study were explained to all participants, and informed consent was obtained from each.

\section{CLINICAL PROCEDURES}

Jejunal biopsies were obtained with a four-hole multipurpose biopsy instrument positioned near the ligament of Treitz under fluoroscopic examination (Brandborg, Rubin, and Quinton, 1959). An average of three specimens was obtained with each biopsy procedure. One specimen from each patient was fixed for microscopic examination. Specimens for study of immunoglobulin synthesis were placed immediately on iced aluminium foil and transferred to the incubation medium within five minutes after being obtained.

\section{INCUBATION CONDITIONS}

Biopsy specimens were incubated with ${ }^{14} \mathrm{C}$-L-leucine in a modified Krebs-Ringer buffer system and processed as previously described (Loeb et al, 1971; Falchuk and Strober, 1972).

\section{ASSAY OF ${ }^{14}$ C-L-LEUCINE INCORPORATION INTO IgA AND IgM IMMUNOGLOBULINS}

The supernatant obtained from biopsy homogenates was analysed for ${ }^{14} \mathrm{C}$-IgA and ${ }^{14} \mathrm{C}$-IgM content as described in detail previously (Falchuk and Strober, 1972). Briefly, anti-IgA and anti-IgM antibodies linked covalently to bromacetyl cellulose were incubated with the supernatant obtained from intestinal homogenates for three hours at $37^{\circ} \mathrm{C}$. The BAC-antibody was then separated from the incubation mixture by filtration on fibreglass filters, washed and placed into scintillation vials for counting. The extent of nonspecific binding of radioactive material to the BAC-anti-Ig was assessed with BAC-anti-Ig previously rendered immunologically inactive with excess nonradioactive immunoglobulin. Values obtained for nonspecific binding with inactivated BAC-anti-IgA and inactivated BAC-anti-IgM were subtracted from the total binding value obtained with active BAC-anti-IgA and active BAC-anti-IgM respectively. The final value was corrected for the amount of tissue protein contained in the specimen (Lowry, Rosebrough, Farr, and Randall, 1951).

ASSAY OF ${ }^{14} \mathrm{C}-L$-LEUCINE INCORPORATION INTO ANTIGLIADIN ANTIBODY

An affinity chromatography technique (Cuatrecasas, 1970) was employed to detect antigliadin activity.
In this technique a molecule is purified or assayed by passage over columns containing materials to which the molecule will specifically bind. The column is first charged with the solution to be assayed and then washed with appropriate buffers to remove nonspecifically bound substances; finally, the column is treated with reagents which release specifically bound molecules. In the present studies the affinity columns were composed of Sepharose 4B (Pharmacia, Uppsala, Sweden) to which was coupled fraction III of a peptic-tryptic digest of gliadin (prepared by the method of Frazer, Fletcher, Ross, Shaw, Sammons, and Schneider, 1959) or other proteins. The cyanogen bromide technique was used to link covalently the various proteins to the Sepharose (Cuatrecasas, 1970; Axén, Porath, and Ernback, 1967). In the usual study, the proteinSepharose was placed into siliconized glass Pasteur pipettes to form small columns $(0.5 \times 2.5 \mathrm{~cm})$. Supernatant from the biopsy homogenates was added to the columns and the latter were then washed with $0.1 \%$ bovine serum albumin (BSA), $0.1 \%$ fetal calf serum (FCS), or $0.1 \%$ gelatin, ${ }^{1}$ in sodium phosphate buffer $0.1 \mathrm{M}, \mathrm{pH} 7 \cdot 2$, to remove the bulk of unbound proteins. Finally, the columns were washed with $6 \mathrm{M}$ guanidine to remove bound radiolabelled protein.

We observed that a small fraction of the total amount of radioactivity placed on protein-Sepharose columns was not eluted with phosphate buffer, regardless of the nature of the radiolabelled protein (eg, ${ }^{14} \mathrm{C}$-protein in homogenate, ${ }^{125} \mathrm{I}-\mathrm{BSA},{ }^{125} \mathrm{I}-$ IGA), or the nature of the protein linked to the Sepharose (eg, BSA, gliadin digest). This radioactivity was, however, eluted with guanidine. It was apparent, therefore, that the guanidine eluate contained nonspecifically held radioactivity (ie, held on the column by mechanisms other than the specific interactions between antibody and antigen), as well as specifically bound radioactivity. To control for such nonspecific retention of radioactivity, affinity chromatography of homogenates on gliadin-Sepharose columns was always run in parallel with chromatography on control columns consisting of BSASepharose or bovine gamma globulin-Sepharose (BGG-Sepharose). Values for the labelled proteins released from the latter columns by $6 \mathrm{M}$ guanidine were subtracted from the values obtained with the gliadin-Sepharose columns to obtain a value for radioactivity specifically bound to the gliadinSepharose columns. In a typical example (patient LM) 1692 counts were released from a BSA-Sepharose column with $6 \mathrm{M}$ guanidine; simultaneously,

${ }^{1}$ The nature of the protein in the washing buffer did not appear to make a difference in the results obtained: comparable data were obtained regardless of which washing buffer was employed. 
2547 counts were released from a gliadin-Sepharose column with $6 \mathrm{M}$ guanidine; therefore a net of 855 counts was bound specifically to the gliadin-Sepharose column.

To exclude the possibility that various Sepharose preparations had differing capacities for nonspecific radioactivity, three separate control columns were prepared (keyhole limpet hemocyanin-Sepharose (KLH-Sepharose), BGG-Sepharose, and BSASepharose) and run in parallel with gliadin-Sepharose. Using the homogenate from patient $\mathrm{MN}$, the value obtained for antigliadin activity was not significantly different, whether BSA-, BGG-, or KLH-Sepharose was employed as the control column.

To ensure that human immunoglobulins would not preferentially bind nonspecifically to gliadin-, BGG-, or BSA-Sepharose, ${ }^{125} \mathrm{I}$-IgA and ${ }^{125} \mathrm{I}$-IgM were prepared (Greenwood and Hunter, 1963) and passed over columns as outlined above. In each case more than $99.5 \%$ of the added counts were eluted with the phosphate buffer. Less than $0.5 \%$ of the added counts adhered nonspecifically to the columns and were subsequently eluted with $6 \mathrm{M}$ guanidine. Thus neither the ${ }^{125}$ I-IgA nor the ${ }^{125}$ I-IgM bound preferentially to either column. The degree of nonspecific binding noted is in the range observed with the ${ }^{14} \mathrm{C}$-protein in the biopsy homogenates, suggesting that nonspecific adherence of radioactivity to Sepharose columns is independent of the molecular weight of the eluate and the protein on the Sepharose.

\section{COUNTING TECHNIQUE}

Radioactivity was counted in a liquid scintillation spectrometer (Packard 3320, Chicago, Illinois). The BAC samples were counted directly on fibreglass filters placed in liquid scintillation vials containing $11 \mathrm{ml}$ of a solution consisting of one part Liquifluor (New England Nuclear Corporation, Boston, Mass.), 5 parts Triton X-100, and 15 parts toluene. The guanidine samples were counted in $20 \mathrm{ml}$ of this solution. Quenching was corrected for by the ratio of counts in two channels produced by an automatic external standard. Samples were counted so that the standard deviation of the observed counts was $1 \%$ or less.

\section{STATISTICAL ANALYSES}

Data were evaluated for statistical significance by means of Student's $t$ test (Bancroft, 1957).

\section{Results}

INCOR PORATION OF ${ }^{14} \mathrm{C}$-L-LEUCINE INTO IgA AND IgM IMMUNOGLOBULINS

Values for the incorporation of ${ }^{14} \mathrm{C}$-L-leucine into
IgA and IgM (hereafter referred to as the IgA and/or IgM incorporation value) by jejunal biopsy specimens are shown in figure 1. IgA and IgM incorporation values for specimens obtained from five of seven patients in remission were within or close to 1 standard deviation of the mean of values for 29 normal individuals (Falchuk and Strober, 1972). All seven patients had a significant rise in both the $\operatorname{IgA}(P<0.02)$ and $\operatorname{IgM}(P<0.01)$ incorporation values after a gluten challenge for six to 12 days.

In contrast to the patient group, when eight control subjects were treated in a similar manner to the patients, that is, placed on a gluten-free diet for 14 to 21 days, biopsied, challenged with gluten and rebiopsied, no difference was detected between preand post-gluten challenge incorporation values (table I).

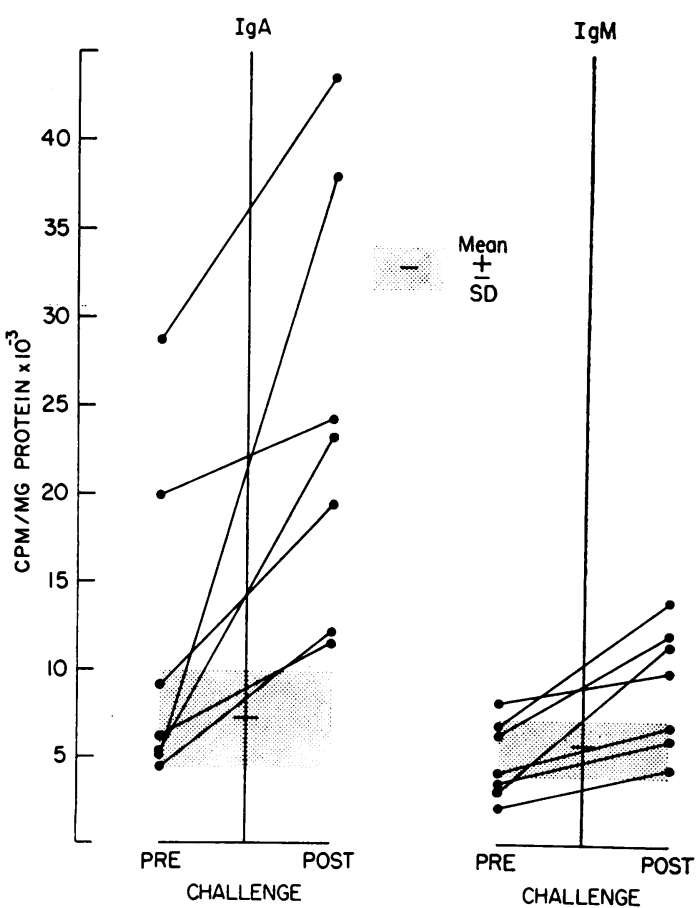

Fig $1{ }^{14} C$ - $L$-Leucine incorporation into $\operatorname{Ig} A$ and $\operatorname{Ig} M$ by jejunal biopsy specimens obtained from patients before and after gluten challenge. The mean $\pm S D$ for 29 normal individuals is shown by the shaded areas. Each point is the result of triplicate determinations. The postchallenge values for $\operatorname{Ig} A$ and $\operatorname{Ig} M$ are significantly greater than the prechallenge values for $\operatorname{Ig} A$ and IgM by paired analysis at $\mathrm{P}<0.02$ and $\mathrm{P}<0.01$ respectively. 


\begin{tabular}{lll}
\hline Individual & $\begin{array}{l}\text { Before Gluten Challenge } \\
\text { (cpm/mg protein) }\end{array}$ & After Challenge \\
\hline DL & 5328 & 6925 \\
HB & 5936 & 7912 \\
AY & 3103 & 3064 \\
KC & 7994 & 8485 \\
MH & 5788 & 1621 \\
SG & 2432 & 3213 \\
JC & 5000 & 8332 \\
RF $^{2}$ & 100 & 110 \\
\hline
\end{tabular}

Table I Incorporation of ${ }^{14} C$ - $L$-leucine into IgA in control individuals before and after gluten challenge

${ }^{1}$ Not significantly different from prechallenge values $(P>0.5$ by paired analysis)

${ }^{2}$ Hypogammaglobulinemia.

Each point represents the mean of two or three determinations.

The effect of gluten on immunoglobulin production in the gastrointestinal mucosa of one patient with GSE was greater than its effect on total protein production. Incorporation into IgA rose fivefold, and into IgM 3.5-fold, whereas incorporation into total protein measured by TCA precipitation (Loeb et al, 1971) increased only $1 \cdot 9$-fold.

\section{INCORPORATION OF ${ }^{14} \mathrm{C}$-L-LEUCINE INTO} MATERIAL WITH ANTIGLIADIN ACTIVITY Biopsy homogenates obtained from the seven patients with GSE while in clinical remission contained no detectable radiolabelled protein binding specifically to a gliadin-Sepharose column. In contrast, homogenates after challenge, from six of seven patients contained clearly and reproducibly detectable radiolabelled protein which bound specifically to the gliadin-Sepharose column (table II). The one patient in whom such binding could not be detected following challenge was subjected to the shortest period of gluten challenge (six days) and, in addition, had the lowest prechallenge immunoglobulin incorporation values.

Biopsies obtained from five normal volunteers studied in a manner identical to those obtained from

\begin{tabular}{lcc}
\hline Patient & \multicolumn{2}{c}{ Specific Binding to Gliadin-Sepharose } \\
\cline { 2 - 3 } & $\begin{array}{l}\text { Before Challenge } \\
\text { (cpm/mg protein) }\end{array}$ & After Challenge \\
& $120 \pm 100$ & $13932 \pm 3078$ \\
LM & 0 & $10726 \pm 750$ \\
MN & $85 \pm 60$ & $15750 \pm 300$ \\
BW & $92 \pm 90$ & $5015 \pm 952$ \\
DR & $105 \pm 100$ & $4074 \pm 1385$ \\
BN & $72 \pm 70$ & $3850 \pm 300$ \\
CG & 0 & 0 \\
GK & 0 & 0 \\
Normal (5) & &
\end{tabular}

Table II Specific binding to gliadin-Sepharose of labelled protein in homogenates obtained from patients with gluten-sensitive enteropathy before and after gluten challenge

${ }^{1}$ Values after challenge significantly greater than values before challenge $(P<0.01)$ by paired analysis.

${ }^{2}$ Number of subjects studied.

Each point represents a mean value \pm SD obtained from three determinations.

patients did not contain radiolabelled protein which bound specifically to gliadin-Sepharose either before or after gluten challenge.

NATURE OF NEWLY SYNTHESIZED MATERIAL WITH ANTIGLIADIN ACTIVITY

The data presented are-consistent with the view that the increased synthesis of immunoglobulins by biopsy specimens obtained from patients after gluten challenge is due to increases in locally produced antibody with specificity for gliadin. Various experiments were done to support this view.

In three patients, IgA and IgM incorporation values were determined by the BAC method before and after passage of homogenate after challenge over either gliadin-Sepharose or BSA-Sepharose columns (table III). In all three patients studied, passage of homogenates over the Sepharose-gliadin column reduced the immunoglobulin incorporation values by an amount predictable from the number of counts binding to gliadin-Sepharose, ascertained

\begin{tabular}{|c|c|c|c|c|c|c|}
\hline \multirow[t]{2}{*}{ Patient } & \multicolumn{3}{|c|}{ Before Challenge (cpm/mg protein) } & \multicolumn{3}{|c|}{ After Challenge (cpm/mg protein) } \\
\hline & $\begin{array}{l}\text { BSA-Sepharose }{ }^{1} \\
\text { (a) }\end{array}$ & $\begin{array}{l}\text { Gliadin-Sepharose } \\
\text { (b) }\end{array}$ & $\Delta^{2}$ & $\begin{array}{l}\text { BSA-Sepharose } \\
\text { (c) }\end{array}$ & $\begin{array}{l}\text { Gliadin-Sepharose } \\
\text { (d) }\end{array}$ & $\Delta^{3}$ \\
\hline $\begin{array}{l}\text { CG } \\
\text { MN } \\
\text { BN }\end{array}$ & $\begin{array}{r}9512 \\
34200 \\
16450\end{array}$ & $\begin{array}{r}9422 \\
34150 \\
16236\end{array}$ & $\begin{array}{r}90 \\
50 \\
214\end{array}$ & $\begin{array}{l}17614 \\
55307 \\
30500\end{array}$ & $\begin{array}{ll}12 & 789 \\
48 & 283 \\
21 & 128\end{array}$ & $\begin{array}{l}4825 \\
7024 \\
9372\end{array}$ \\
\hline
\end{tabular}

Table III ${ }^{14} C$-Ig $A+{ }^{14} C$-IgM incorporation values obtained after passage of biopsy homogenates over protein-Sepharose

${ }^{1} \mathrm{C}-\mathrm{IgA}+{ }^{14} \mathrm{C}$-IgM incorporation values obtained after passage over BSA-Sepharose columns were the same as those determined using untreated homogenate.

${ }^{2}$ Difference (a-b) not significant by paired analysis.

Difference (c-d) significant $(P<0.05)$ by paired analysis.

Each point is the mean of triplicate determinations. 
previously in the assay for antigliadin activity. In contrast, passage of homogenate over BSASepharose columns had no effect on the $\operatorname{IgA}$ and IgM incorporation values. Employing homogenates before challenge, no significant changes were produced in the incorporation values by passage over either BSA- or gliadin-Sepharose. In a fourth patient the converse study was done. Radiolabelled proteins binding to BAC anti-IgA and anti-IgM, ie, IgA and IgM, were removed from the homogenate by prior incubation with BAC anti-IgA and BAC anti-IgM; the homogenate was then passed over the gliadin- and BSA-Sepharose columns, and the amount of radiolabelled protein specifically binding was compared with the amount obtained using a specimen that had not been previously incubated with BAC-anti-Ig. It was found that preincubation with BAC-anti-IgA and IgM resulted in a $60 \%$ decrease in specific binding to the gliadin-Sepharose column. In contrast, preincubation of homogenate with immunologically inactivated BAC-anti-Ig did not alter specific binding to gliadin-Sepharose columns.

These experiments support the view that a significant portion of the postgluten challenge increase in mucosal immunoglobulin synthesis is composed of immunoglobulin with antigliadin specificity. We can therefore compare our estimates for the value for net increase in local immunoglobulin production following gluten challenge in vivo (that is, the value for incorporation into IgA and IgM after challenge less the value for incorporation into $\operatorname{IgA}$ and $\operatorname{IgM}$ before challenge) with estimates for the value of antigliadin antibody production observed after the challenge period. This comparison, shown in fig 2, indicates that for six of seven patients, 29 to $75 \%$ of the increased immunoglobulin production is due to antigliadin antibody synthesis.

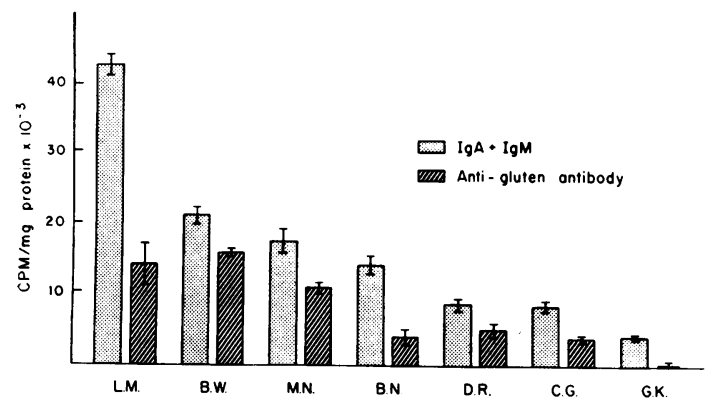

Fig 2 Net increase of ${ }^{14} C-I g A+{ }^{14} C-I g M[($ postchallenge ${ }^{14} C$-Ig $A+{ }^{14} C$-IgM $)-\left(\right.$ prechallenge ${ }^{14} C$ - $I g A$ $+{ }^{14} C$-IgM)] compared with total amount of antigliadin antibody activity appearing after gluten challenge. Each bar represents the mean $\pm S D$ of three determinations.

\section{Discussion}

Patients with gluten-sensitive enteropathy in remission respond to the ingestion of gluten with an increase in jejunal production of IgA and IgM immunoglobulins, and a major portion of this increase is attributable to antigliadin antibody. The estimate in the present study of local antigliadin production and its relation to the total immunoglobulin response is probably a minimal estimate since the antigen used to detect antigliadin activity was a peptic-tryptic digest of gliadin which may not contain the full spectrum of antigenic determinants of the gliadin molecule. Furthermore, in our effort to measure only specific binding to gliadin-Sepharose it is possible that the washing procedure removes some of the low-affinity antigliadin antibody from the columns.

Patients with gluten-sensitive enteropathy may have circulating antibodies directed at gluten or gluten extracts (Taylor, Thomson, Truelove, and Wright, 1961; Heiner, Lahey, Wilson, Gerrard, Shwachman, and Khaw, 1962). Though this finding was initially thought to be aetiologically significant, its importance was questioned when it was demonstrated that patients with gluten-sensitive enteropathy also had circulating antibodies to other food constituents (Taylor et al, 1961; Heiner et al, 1962; Alarcon-Segovia, Herskovic, Wakim, Green, and Scudamore, 1964; Kenrick and Walker-Smith, 1970). Recently, attention has been focused on antibody present in the intestinal secretions of patients with gluten-sensitive enteropathy since the presence of these antibodies in secretions implies their local synthesis. Katz, Kantor, and Herskovic (1968) found antibodies to a peptic-tryptic digest of gliadin in the stool and jejunal secretion of 12 patients with gluten-sensitive enteropathy, but not in specimens collected from normal or other control individuals. Ferguson and Carswell (1972) have confirmed that patients with this disorder do indeed have antigluten antibodies as well as other antifood substance antibodies in stool and jejunal secretions. However, these antibodies were also present in patients not having gluten-sensitive enteropathy, suggesting that they were not related to the disease process. A critical question raised by these studies of antibodies in secretion and stool concerns the origin of the antibody detected. It is possible that such antibodies are derived from the circulation and are not locally produced. In the present study we show that regardless of whether serum or secretion antibody is present or absent, patients with gluten-sensitive enteropathy and not normal persons can and do produce a local antibody response to gluten. The response occurs within the intestinal mucosa where 
the pathological process is taking place, and it occurs early during the gluten challenge. The role of locally produced antigliadin antibodies in the pathogenesis of gluten-sensitive enteropathy remains to be determined. Of central importance is the question of whether the synthesis of these antibodies represents the primary pathological event in glutensensitive enteropathy or whether the synthesis is a secondary phenomenon which does or does not mediate the tissue injury seen in these patients. Indeed the possibility exists that the intestinal mucosa may synthesize not only antigluten antibodies but also antimilk, and other antidietary antibodies.

The pathogenicity of the antigluten antibodies may be further elucidated employing an organ culture model system recently developed by us (Falchuk, Gebhard, Sessoms, and Strober, 1974). We believe that the mucosal immune response may be conditioned by the presence of an immune response gene or of a cell surface receptor, which facilitates a local immune response. This possibility is supported by the presence of a high incidence (80-88\%) of histocompatibility antigen HLA-8 in patients with gluten-sensitive enteropathy (Falchuk, Rogentine, and Strober, 1972; Stokes, Asquith, Holmes, Mackintosh, and Cooke, 1972).

We wish to thank Drs S. Agus, R. Gebhard, and J. Poole for assistance in clinical evaluation of these patients; Dr L. Laster for his encouragement and advice; and Mrs Clementine Sessoms for expert technical assistance.

Dr Falchuk is supported in part by a grant from the Nelson E. Weeks Fund, and a grant from the National Institutes of Health, 1 RO1AM 17684-01.

\section{References}

Alarcon-Segovia, D., Herskovic, T., Wakim. K. G., Green, P. A., and Scudamore, H. H. (1964). Presence of circulating antibodies to gluten and milk fractions in patients with nontropical sprue. Amer. J. Med., 36, 485-499.

Axén, R., Porath, J., and Ernback, S. (1967). Chemical coupling of peptides and proteins to polysaccharides by means of cyanogen halides. Nature (Lond.), 214, 1302-1304.

Bancroft, H. (1957). Introduction to Biostatistics, p. 172. HoeberHarper, New York.

Brandborg, L. L., Rubin, C. E., and Quinton, W. E. (1959). A multipurpose instrument for suction biopsy of the esophagus, stomach, small bowel, and colun. Gastroenterology, 37, 1-16.

Cuatrecasas, P. (1970). Protein purification by affinity chromatography: derivatizations of agarose and polyacrylamide beads. J. biol. Chem., 245, 3059-3065.

Falchuk, Z. M., Gebhard, R. L., Sessoms, C. S., and Strober, W. (1974). An in vitro model of gluten sensitive enteropathy: the effect of gliadin on intestinal epithelial cells in organ culture. J. clin. Invest., 53, 487-500.

Falchuk, Z. M., Rogentine, G. N., and Strober, W. (1972b). Predominance of histocompatibility antigen HL-A8 in patients with gluten-sensitive enteropathy. J. clin. Invest., 51, 1602-1605.

Falchuk, Z. M., and Strober, W. (1972). Increased jejunal immunoglobulin synthesis in patients with nontropical sprue as measured by a solid phase immunoadsorption technique. J. Lab. clin. Med., 79, 1004-1013.

Ferguson, A., and Carswell, F. (1972). Precipitins to dietary proteins in serum and upper intestinal secretions of coeliac children. Brit. med. J., 1, 75-77.

Frazer, A. C., Fletcher, R. F., Ross, C. A. C., Shaw, B., Sammons, H. G., and Schneider, R. (1959). Gluten-induced enteropathy: the effect of partially digested gluten. Lancet, 2, 252-255.

Greenwood, F. C., and Hunter, W. M. (1963). The preparation of 131I-labelled human growth hormone of high specific radioactivity. Biochem. J., 89, 114-123.

Heiner, D. C., Lahey, M. E., Wilson, J. F., Gerrard, J. W., Shwachman, H., and Khaw, K. T. (1962). Precipitins to antigens of wheat and cow's milk in celiac disease. J. Pediat., 61, 813830 .

Katz, J., Kantor, F. S., and Herskovic, T. (1968). Intestinal antibodies to wheat fractions in celiac disease. Ann. intern. Med., 69, 1149-1153.

Kenrick, K. G., and Walker-Smith, J. A. (1970). Immunoglobulins and dietary protein antibodies in childhood coeliac disease. Gut, 11, 635-640.

Loeb, P. M., Strober, W., Falchuk, Z. M., and Laster, L. (1971). Incorporation of $\mathrm{L}$-leucine-1" $\mathrm{C}$ into immunoglobulins by jejunal biopsies of patients with celiac sprue and other gastrointestinal diseases. J. clin. Invest., 50, 559-569.

Lowry, O. H., Rosebrough, N. J., Farr, A. L., and Randall, R. J. (1951). Protein measurement with the Folin phenol reagent. J. biol. Chem., 193, 265-275.

Taylor, K. B., Thomson, D. L., Truelove, S. C., and Wright, R. (1961). An immunological study of coeliac disease and idiopathic steatorrhoea. Serological reactions to gluten and milk proteins Brit. med. J., 2, 1727-1731.

Stokes, P. L., Asquith, P., Holmes, G. K. T., Mackintosh, P., and Cooke, W. T. (1972). Histocompatibility antigens associated with adult coeliac disease. Lancet, 2, 162-164. 